\title{
Understanding spirituality from positive psychology: Culture specificity of lived experience
}

De la Peña, Yayetta C. $\$

Department of Psychology, Xavier University-Ateneo de Cagayan,

Cagayan de Oro, Philippines (yayetdelapena@yahoo.com)

Received: 10 November 2012

Revised: 15 December 2012 Available Online: 30 December 2012 DOI: $10.5861 /$ ijrsp.2012.265

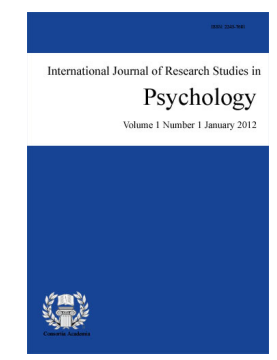

ISSN: $2243-7681$

Accepted: 22 December 2012

OPEN ACCESS

\section{Abstract}

Spirituality as a subjective experience, intrinsic, and central to people's well-being is underscored. Positive Psychology is presented as a possible framework for explaining the relationship between spirituality and well-being. However, for a more coherent understanding of the nature of spirituality, recommendation for a process-based rather than an outcome-based approach is made. As such, focus is shifted from identifying behavioral indicators and values check-list to studying people's lived experience of spirituality. Rather than plain descriptive, the approach is believed to yield in-depth results that are more explicatory of the nature of spirituality. Moreover, the cultural specificity of spirituality is stressed. Viewed and actually practiced differently from culture to culture, a call to examine similarities and variations of psychological processes across cultures is proposed. Implications of the approaches to clinical practice and test development are indicated.

Keywords: culture-specific, individualism-collectivism, lived experience, spirituality 


\section{Understanding spirituality from positive psychology: Culture specificity of lived experience}

\section{Introduction}

Spirituality signifies an individual's connectedness with the transcendent, self, others, and nature; a search for meaning and purpose in life (Meezenbroek, Garssen, van den Bers, van Dierendonck, Visser, \& Schaufeli, 2012; Chiu, Emblen, Van Hofwegen, Sawatzky, \& Meyerhoff, 2004). Connectedness with the transcendent includes seeking unity with the "sacred," an Ultimate Reality, a higher power, or God. Connectedness with the self is expressed in several ways such as authenticity, sense of wholeness, meaningful identity, self-knowledge, and ability to draw from one's inner strengths, among others. Connectedness with others and with nature is related to a sense of community, compassion, altruism, caring, gratitude and wonder. The search for meaning is reflected in an individual's making sense of life and one's experiences, of seeking answers to ultimate questions about life's meaning and purpose (Chiu et al., 2004). This meaning gives hope, inner peace, and sense of direction. Taken as a whole, a testimony of one's spirituality is a "lifestyle that incorporates one's response to the picture of the sacred" (Hill, Pargament, Hood, McCollough, Swyers, Larson, \& Zinnbauer, 2000). This lifestyle is characterized by personal growth and a valuing of others (Chiu et al. 2004).

\section{Discussion}

Intrinsic to human nature, spirituality is central and important to people's lives (Del Rio \& White, 2012). Spirituality's centrality to human existence is evident in the large number of researches devoted to its study. Various theories and models of spirituality were created in the effort to explain the phenomenon. To cite, the science of Positive Psychology specifically recognizes spirituality's role in promoting the well-being and optimal functioning of an individual (Duckworth, Steen, \& Seligman, 2005). Well-being or happiness is a central concept in Positive Psychology. Accordingly, well-being or happiness has three facets/domains, namely, the pleasant life, the engaged life, and the meaningful life. The pleasant life is concerned with the positive emotion about the past (e.g., contentment, satisfaction, and serenity), the present (e.g., somatic pleasures like immediate but momentary sensory delights, and the complex pleasures like those obtained in learning and education, and the future (e.g., optimism, hope, and faith).

The engaged life is characterized by the use of character strengths. The third domain of happiness, the meaningful life, involves the pursuit of meaning as one uses his/her character strengths by belonging to and serving institutions (e.g., family and friends, community, church, organizations, and nation). People are most satisfied when the three types of life/happiness are pursued; more so when emphasis is placed on engagement and meaning. Central to Positive Psychology's concept of well-being or happiness are character strengths defined as "qualities considered virtuous across cultures and historical eras" (Duckworth, Steen, \& Seligman, 2005). In particular, spirituality is regarded as character strength (Peterson \& Seligman, 2004). Spirituality shapes values of human decency that informs each person's decision and relationships (East, 2005). It leads individuals to practice deeply held values that benefit not only the self but others as well.

Empirical studies have been conducted to test the empirical validity of the theories on spirituality, particularly its role in promoting the well-being of individuals. Rightly so, quality of life studies did point to a predictive relationship between spirituality and well-being (Sawatzky, Ratner, \& Chiu, 2005). Spirituality is shown to impact a person's health outcome, facilitate successful coping through a meaning-making process, engender positive affect, and promote prosocial behaviors.

Yet, how well-being is sought and what aspect of well-being is valued is a matter of clarification. As it is, well-being can be sought in different ways as there are different roads to pursuing it, either through the pleasant 
life, the engaged life, or the meaningful life (Duckworth, Steen, \& Seligman, 2005). For instance, a person might experience well-being or happiness from the following: achievement of closure of a painful experience, enlightenment and victory over obstacles in one's endeavors, a sense of inner peace, a promising future, or a mystical experience and a sense of awe and wonder over nature (pleasant life). It is also possible to achieve well-being by exercising virtuous qualities like leadership, kindness, integrity, originality, wisdom, and the capacity to love and be loved (engaged life). Some others find happiness when they live life meaningfully by selflessly exercising their strengths to benefit others (meaningful life).

From the preceding thoughts, one can argue that well-being is a subjective experience which may differ from person to person. A person's choice is often influenced by what other individuals consider to be the more beneficial "road". In effect, what well-being means and how it is realized may be socialized or negotiated by what is culturally valued, thus may vary across cultures. By the same token, spirituality, as character strength and a potent source of well-being, may be perceived and experienced in different ways from culture to culture. In a given culture, differences may be present, yet commonalities are more dominant as people's behaviors are socially coordinated. On this note, we highlight culture's role in teaching individuals how to think, act, feel, and interact with others. People learn different implicit theories through socialization (Keesing, 1974). These theories include, among others, people's religious beliefs, values and practices. In sum, how a person views and practice spirituality is shaped by and shared with the culture where he/she belongs.

Social psychologists argued that shared values influence a person's cognitive, emotional, and social functioning (Cooper \& Denner, 1998). Over the years, several dimensions of culture were explored to differentiate cultures. The Individualism-Collectivism is a dimension particularly relevant to the study of spirituality. It distinguishes groups based on their individualist and collectivist values that are "seen in shared attitudes, beliefs, norms, role and self-definitions, and values of members of each culture" (Cooper et al., 1998). Relevant features of individualism include valuing personal independence by putting an emphasis on personal responsibility and freedom of choice, personal autonomy, initiative, achieving self-fulfillment and self-actualization, uniqueness from others, and self-directed behaviors (Galanes \& Adams, 2007). Meanwhile, collectivism assumes integrated and cohesive in-groups that emphasize a sense of duty to the group, interdependence, harmony, and collective accountability. Western cultures identify more with individualism while East Asian cultures identify more with collectivism (Forsyth, 2010).

One specific element of culture that differentiates individualists from collectivists is the value placed on feelings as information (Kwon, 2008). As reported, in individualistic culture, ability to feel and express feelings is emotionally relieving and contributes to a sense of well-being. Subjective feelings and experience are considered valuable aids in decision making. In contrast, collectivistic cultures which value relationships would want to maintain positive ties by being sensitive to another's feelings, hence, direct expression of emotions is not much observed. The same is true with a collectivist Filipino culture that values smooth interpersonal relationships or "pakikiramdam" (Pe-Pua \& Protacio-Marcelino, 2000). Filipinos have a propensity for indirect communication. Another differentiating cultural factor cited by Kwon (2008) is the regard for standards of normative behaviour. On this particular point, East Asian cultures are inclined toward adherence to these norms. Similarly, Filipino culture, keen to maintain a sense of propriety (Pe-Pua \& Protacio-Marcelino, 2000) are more inclined to follow rules and traditions, thus, may be observed to manifest organizational religiousness. How one relates with others is especially valued. Specifically, group goals and expectations are above an individual's lead. In Filipino culture this is exemplified in the Filipino value of helping others or "pakikipagkapwa" or "bayanihan" (Pe-Pua \& Protacio-Marcelino, 2000). Among individualists, an individual's lead is recognized. Also a defining element is the nature of emotions felt. Accordingly, individualist's emotions are more "ego-focused," while that of collectivists, as studied by Markus and Kitayama (Kwon, 2008) are "other-focused."

Ego-focused emotions are reflected in a person's sense of pride, while other-focused emotions are reflected in one's consideration of other people's feelings. Where spirituality is concerned, the cultural perspectives are 
also apparent in terms of how cultures view the phenomenon. For instance, in Western societies where self-autonomy and independence are the cultural ideals, individual/privatized spirituality is valued more than it is with Eastern societies. Specifically, meditation in Western culture may be regarded as a way to "cultivate the internal self and deal with the inner turmoil of emotion" that calms the self and brings a sense of personal happiness and well-being (ego-focused) (Kwon, 2008). In a collectivist culture, meditation is a way to practice interdependence with others (other-focused) given the value placed on social relationships and harmony. People in a collectivistic culture also believe it is important to consider others in their prayers than praying only for their selves. Same is true for the collectivist Filipino culture which views spirituality as relational, with love of God translated into love of others, with "love of self hardly mentioned but obliquely noted" (Yalung, 2010).

Individualism-Collectivism is appropriately viewed as continuous and varying in degree such that no culture is purely collectivist or individualist. This is exemplified by the pluralistic nature of most societies to date where borrowing of practices (spiritual practices included) and adoption of beliefs from one culture to another is prevalent. Thus, labelling any group or community as individualist or collectivist by virtue of the country of origin without considering these dynamics could lead to misguided generalizations. There are also variations in the emphasis of different collectivistic cultures. To account for these variations, Triandis, Bhawuk, and Gelfand proposed the vertical and horizontals sub-dimensions of Individualism-Collectivism dimension (Shiraev \& Levy (2001). On one hand of the continuum, there is a Horizontal Individualism with the self perceived as independent yet the same as others, and a Vertical Individualism with the self as valued but seen as different from others. On the other hand of the continuum is a Horizontal collectivism with the self as interdependent and similar to others, and a Vertical collectivism with the self as interdependent, yet unequal with the others. Service and sacrifice is observed. Noting these variations would help explain the intricacies about the phenomenon under study.

\section{Conclusion}

In conclusion, spirituality has always attracted a huge interest among scholars in related fields of discipline. Concomitant to this wide following are the different approaches by which spirituality is studied, and varying conceptualizations of the nature of spirituality. Nonetheless, spirituality as a subjective experience and as culture-specific are salient points of argument in understanding spirituality. These two arguments point to several implications that may affect attempts for a generalizable and comprehensive conceptualization of spirituality. In particular, the subjective nature of the experience poses a problem in the creation of a universal definition. Spirituality means different things from person to person.

As noted, most approaches in the study of spirituality were more outcome-based than process-based. A person's spirituality or the absence thereof tends to be based on a checklist of values and behavioral indicators that limits a more insightful understanding as to how spirituality is experienced and under what conditions the experience arises. The outcome-based approach is lamented as limited in explaining the experience and essence of spirituality. Equally notable is the cultural specificity in terms of how spirituality is viewed and actually practiced by a particular group of individuals. It is clear that the notion of spirituality in one culture cannot be generalized to other cultures. Creating additional weight to the implications is the observed obvious need to account for the similarities and variations on how spirituality is understood across cultures.

From the preceding concerns, it would be provisionally important for future research directions to examine community-specific psychological process or processes that would explain the culture-specific nature of spirituality. In addition, future investigations could use a process-based approach to study spirituality through a specific focus on the lived experiences of people in a given culture. Rather than plain descriptive, the method could yield in-depth results that are more explicatory. Overall, consideration of the arguments presented would optimistically lead to the creation of a more coherent model of spirituality that is substantially grounded on context-specific factors. 
Beyond the creation of a coherent paradigm would be its subsequent impact on practitioners. Among mental health professionals spirituality is identified as a place for healing and wholeness (Fukuyama, 2003). As such, integration of spiritual competence in addressing spiritual issues of clients is called for. This need is more expressed in the area of multicultural counseling where cultural empathy is an essential key to the counseling process.

\section{References:}

Chiu, L., Emblen, J., Van Hofwegen, L., Sawatzky, R., \& Meyerhoff, H. (2004). An integrative review of the concept of spirituality in the health sciences. Western Journal of Nursing Research, 26, 405-428. http://dx.doi.org/10.1177/0193945904263411

Cooper, C., \& Denner, J. (1998). Theories linking culture and psychology: Universal and community-specific processes. Annual Review in Psychology, 49, 559-84. http://dx.doi.org/10.1146/annurev.psych.49.1.559

Del Rio, C., \& White, L. (2012). Separating spirituality from religiosity: A hylomorphic attitudinal perspective. Psychology of Religion and Spirituality, 4, 123-142. http://dx.doi.org/10.1037/a0027552

Duckworth, A. L., Steen, T., \& Seligman, M. (2005). Positive psychology in clinical practice. Annual Review in Clinical Psychology, 1, 629-651. http://dx.doi.org/10.1146/annurev.clinpsy.1.102803.144154

East, T. (2005). A grounded theory on how spirituality in the workplace impacts a person's job satisfaction. (Master's thesis). Retrieved from Proquest Digital Dissertations \& Theses database (Publication No. AAT 3168180).

Forsyth, D. (2010). Group dynamics (5 ${ }^{\text {th }}$ ed.). USA: Wadsworth, Cengage Learning.

Fukuyama, M. (2003). Culture and counseling: New approaches. Needham Heights, MA: Allyn \& Bacon. Galanes, G., \& Adams, K.(2007). Effective group discussion: Theory and practice (12 ${ }^{\text {th }}$ ed). NY:McGraw-Hill.

Hanna, F., \& Green, A. (2004). Asian shades of spirituality: Implications for multicultural school counseling. Professional School Counseling, 7, 326.

Hill, P., Pargament, K., Hood, R. Jr., McCollough, M., Swyers, J., Larson, D., \& Zinnbauer, B. (2000). Conceptualizing religion and spirituality: points of commonality, points of departure. Journal for the Theory of Social Behavior, 30, 1. http://dx.doi.org/10.1111/1468-5914.00119

Keesing, Roger (1974). Theories of culture. Annual Review of Anthropology, 3, 73-97. http://dx.doi.org/10.1146/annurev.an.03.100174.000445

Kwon, S. (2008). Well-being and spirituality from a Korean perspective: Based on the study of culture and subjective well-being. Pastoral Psychology, 55, 573-584. http://dx.doi.org/10.1007/s11089-008-0134-1

Meezenbroek, E., Garssen, B., van den Bers, M., van Dierendonck, D., Visser, A., \& Schaufeli, W. (2012). Measuring spirituality as a universal human experience: A review of spirituality questionnaires. Journal of Religious Health, 51, 336-354. http://dx.doi.org/10.1007/s10943-010-9376-1

Pe-Pua, R., \& Protacio-Marcelino, E. (2000). Sikolohiyang Pilipino (Filipino psychology): A legacy of Virgilio G. Enriquez. Asian Journal of Social Psychology, 3, 49-71. http://dx.doi.org/10.1111/1467-839X.00054

Peterson, C., \& Seligman, M. (2004). Character strengths and virtues: A handbook and classification. NY: Oxford University Pages, Inc.

Sawatzky, R., Ratner, P., \& Chiu, L. (2005). Meta-analysis of the relationship between spirituality and quality of life. Social Indicators Research, 75,153-188. http://dx.doi.org/10.1007/s11205-004-5577-x

Shiraev, E., \& Levy, D. (2001). Cross-cultural psychology. Needham Heights: Allyn and Bacon.

Yalung, C. (2010). The contribution and influence of spirituality and religion on Filipino caregivers' motivations and services. (Master's thesis). Retrieved from http://hdl.handle.net/10211.9/214 
De la Peña, Y. C. 